\title{
Influence of drying on in vitro gastric digestion of beetroot: evaluation of the microstructure
}

\author{
Dalmau, M. E. ${ }^{\text {a }}$ Carcel, J. A. ${ }^{\text {; }}$ Eim, V. ${ }^{\mathbf{a}^{*}}$; Simal, S. ${ }^{\text {a }}$
}

a Department of Chemistry. University of the Balearic Islands, Palma, Spain.

b ASPA group. Department of Food Technology. Universitat Politècnica de València, Valencia, Spain

*E-mail of the corresponding author: valeria.eim@uib.es

\begin{abstract}
To better understand the influence of processing on the bioaccessibility of bioactive compounds during digestion, the microstructure of beetroot samples was observed prior to and after 180 min of in vitro digestion, by using scanning electron microscopy. Beetroot samples were subjected to convective drying at $60{ }^{\circ} \mathrm{C}$ and $2 \mathrm{~m} / \mathrm{s}$ and freeze-drying at $-50{ }^{\circ} \mathrm{C}$ and $30 \mathrm{~Pa}$. Dried beetroots were rehydrated prior to digestion by immersion in distilled water at $37^{\circ} \mathrm{C}$ during 90 min. To extract quantitative information related to cell size from the visual texture of beetroot, grey level granulometric methods from mathematical morphology were applied.
\end{abstract}

Keywords: freeze drying; convective drying; scanning electron microscopy; image analysis; image texture analysis. 


\section{Introduction}

The nutritional values of plant foods are usually estimated according to their natural concentrations of nutrients, phytochemicals, and total antioxidant activity. These data are usually obtained by direct extraction with organic solvents. ${ }^{[1]}$ However, these conditions are different from the physiological conditions that occur in the digestive tract. Furthermore, the biological properties of bioactive compounds found in vegetables depend on their bioaccessibility and bioavailability. ${ }^{[2]}$ Bioaccessibility refers specifically to the quantity of nutrients which are released from the food matrix and presented to the intestinal brush border for transport into the cell. ${ }^{[3]}$ Meanwhile, bioavailability refers to the quantity of nutrients which actually pass through the cell membrane and are available for use within the cell. ${ }^{[4]} \mathrm{It}$ is known that the influence of processing on food may be the result of cellular and structural changes. For example, freeze drying and convective drying have been shown to cause cellular changes in the food matrix. Huang et al. ${ }^{[5]}$ found that freeze drying $\left(-40{ }^{\circ} \mathrm{C}, 100 \mathrm{~Pa}\right)$ in a microwave vacuum dryer (75-300 W, $5 \mathrm{kPa}$ ) resulted in cell wall shrinkage in apples (var. Red Fuji). Moreover, there is wide evidence that the physical state of the food matrix plays a key role in the release, mass transfer, accessibility, and biochemical stability of many food components. ${ }^{[6]}$

Microscopy is a useful tool for visualizing food structure at the tissular and cellular levels and for studying the influence of processing on in vitro digestion. ${ }^{[7,8]}$ The characterization of samples by imaging techniques is completed by applying image analysis to quantify the structure observed. Techniques based on image texture analysis can be envisioned in order to quantify information on object size. There are four different types of image texture analysis: structural texture, statistical texture, model-based texture and transform-based texture. Among them, statistical texture is the most widely used in the food industry for its high accuracy and less computation time. Statistical texture, has been successfully applied to extract quantitive information related to cell size ${ }^{[9]}$. The methodology of statistical texture reflects changes in the intensity values of pixels. These may well contain information about the geometric structure of objects as this can be often reflected by such a change in intensity values. In food images, texture can, to some extent, reflect cellular structure of foodstuffs and thus can be used as an indicator of food quality. For example, texture can be used to reveal the tenderness of beef when colour and size features are not adequate. For this reason, among the large scale of applications of image analysis in the food industry, which is one of the top ten industries using computer vision, texture has been used regularly and its usage covers a variety of foods including baked products, cereal grains, fruits and vegetables. ${ }^{[10]}$

Thus, the objective of this study was to evaluate the effects of different drying methods and in vitro gastric digestion on the microstructure of beetroots (Beta Vulgaris) with image texture analysis using a statistical texture methodology. 


\section{Materials and Methods}

\subsection{Samples}

Beetroot (Beta vulgaris var. conditiva) were purchased from a local supermarket (initial moisture content of $6.67 \pm 0.04 \mathrm{~g}$ water/g dm and total soluble solids of $\left.10.8 \pm 0.4{ }^{\circ} \mathrm{Brix}\right)$. The beetroot were stored at $4{ }^{\circ} \mathrm{C}$ for a maximum of one week. Cubes were cut ( $0.01 \mathrm{~m}$ edge) from the center regions of the beetroot tissue, not including the peel, and immediately processed.

\subsection{Convective drying and freeze drying processes}

Convective drying (CD) was carried out in a laboratory-scale hot air dryer previously described by Rodríguez et al. ${ }^{[11]}$ operating at $60{ }^{\circ} \mathrm{C}$ with an air velocity of $2 \mathrm{~m} / \mathrm{s}$. Samples were dried until a final moisture content of $0.17 \pm 0.03 \mathrm{~g}$ water $/ \mathrm{g} \mathrm{dm}$. Freeze drying (FD) of beetroot cubes was carried out in a freeze-drier (Telstar LyoQuest, Spain) operating at -50 ${ }^{\circ} \mathrm{C}$ and a vacuum pressure of $30 \mathrm{~Pa}$ until a final moisture content of $0.07 \pm 0.01 \mathrm{~g}$ water/g $\mathrm{dm}$. Before in vitro digestion, $\mathrm{CD}$ and FD samples were rehydrated by immersion in distilled water (25:100 (g beetroot/ml water)) at $37^{\circ} \mathrm{C}$ until they reached final moisture content similar to raw samples (6.67 $\pm 0.04 \mathrm{~g} / \mathrm{g} \mathrm{dm}$ ) (aprox. 90 and $80 \mathrm{~min}$, respectively).

\subsection{In vitro digestion procedure}

The beetroot samples were digested following the in vitro gastric digestion method reported by Bornhorst \& Singh ${ }^{[12]}$. Beetroot cubes (ca. 200 g) were mixed with $80 \mathrm{ml}$ of simulated saliva for $30 \mathrm{~s}$, followed by immersion in $800 \mathrm{ml}$ of simulated gastric juice previously heated to $37^{\circ} \mathrm{C}$. The mixture was incubated in a shaking water bath (Unitronic $320 \mathrm{OR}$, Selecta, Spain) at $37^{\circ} \mathrm{C}$ and $100 \mathrm{rpm}$ for up to $3 \mathrm{~h}$. Samples were taken initially (no digestion), and after 180 min of gastric digestion, microstructural analyses were made.

\subsection{Microstructural analysis}

\subsubsection{Scanning electron microscopy (SEM)}

Cell walls were observed by SEM of raw and drying samples before and after digestion. Beetroot cubes were soaked in liquid nitrogen in order to be fractured with a sharp razor blade, and freeze dried. Gold coating was performed using (E-5400, Polaron, UK) equipment (10-4 mbar, $20 \mathrm{~mA}$, 80s). Samples were then observed in a S-3400N Hitachi SEM (Germany), accelerated at $15 \mathrm{kV}$ and under a vacuum pressure of $40 \mathrm{~Pa}$.

\subsubsection{Image texture analysis}

To quantify the effect of drying and gastric in vitro digestion on the beetroot structure, cell cavities of the raw and drying cubes before (CD and FD samples) and after (raw180, CD180 and FD180) 180 min of gastric in vitro digestion, were characterized in terms of their cell area and cell number per unit of area. Thus, scanning electron microscope photographs were analyzed by using an automatic image processing method which is based on the statistical 
texture method and was performed using Image J 2.0.0. software. (Creative commons license). The real cell area value was correlated to a standard image whose dimensions were known. To establish a representative structural analysis, fifteen scanning electron microscope photographs of each sample were analyzed. ${ }^{[9]}$

Statistical analysis of the results was perfomed by using the "prctile" function of Matlab 2017b software (Mathworks Inc., USA). Thus, the percentile profile of cell number per unit of area of each sample was obtained. Analysis of variance (ANOVA) was applied to analyze the effects of processing in respect of the raw sample and the effects of in vitro digestion on microstructure parameters. Means were compared by Tukey's test at $\mathrm{p}<0.05$.

\section{Results and discussion}

\subsection{Microstructural images (SEM)}

The images of raw and processed samples before and after $180 \mathrm{~min}$ of in vitro gastric digestion are shown in Fig 1. Fig $1 \mathrm{a}_{1}$ shows the microstructure of raw samples prior to in vitro gastric digestion. The raw samples are composed of almost isodiametrical and polyhedral cells with few intercellular spaces, as was previously observed by Nayak et al. ${ }^{[7]}$. After 180 min of digestion (Fig $1 \mathrm{a}_{2}$ ) a significant cell lysis was observed, resulting in a smaller number of cells per unit area, along with increases in the intercellular space between remaining cells. Carnachan et al. ${ }^{[8]}$ studied the microstructure of kiwi pulp after in vitro gastric digestion observed an increase in the intercellular space after in vitro digestion.

Cells exhibited shrinkage during the convective drying process, as can be observed in Fig $1 b_{1}$, resulting in a greater disruption of the cellular structure than in raw samples. The effects of different convective drying conditions on the microstructure of apple have been previously evaluated. ${ }^{[13]}$ These authors agreed that during drying, one of the most important phenomena is cell shrinkage, which leads to a major modification of the product structure and allows the release of water. Convective drying causes cells to rupture and dislocate which usually results in increased density with varying porosity. ${ }^{[14]}$ It was also observed that cell shrinkage increased in CD samples after in vitro gastric digestion (Fig $1 \mathrm{~b}_{2}$ ), completely eliminating the open pores on the surface of the structure and rupturing many of the interior cell walls. 

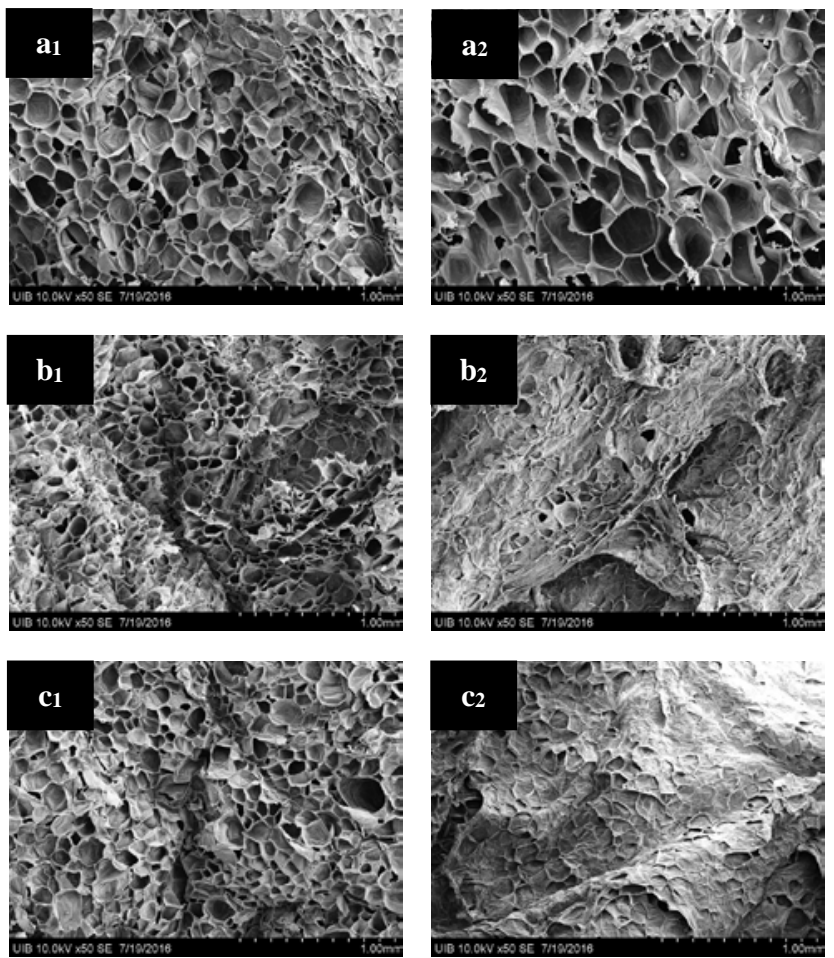

Fig. 1. SEM images of beetroot samples: a-Raw, b-CD and c-FD. 1- of initial beetroot samples (prior to in vitro digestion). 2-after 180 min of in vitro gastric digestion

Fig $1 \mathrm{c}_{1}$ shows the microstructure of FD samples before in vitro digestion. A certain disruption of the cell structure was observed. This effect was also observed by Huang et al. ${ }^{[5]}$ in freezedried Red Fuji apples, and in freeze-dried Idared apple by Lewicki \& Pawlak. ${ }^{[15]}$ An increase in the destruction of cell wall material can be observed as a result of the in vitro gastric digestion process (Fig $1 c_{2}$ ). These changes resulted in almost a complete elimination of the initial porous structure seen in undigested, raw beetroots. The same result was observed by Dalmau et al. ${ }^{[16]}$ in freeze dried Granny Smith apples after 180 min of in vitro gastric digestion, when the changes during digestion eliminated most of the pore structure observed in undigested raw apples. Overall, microstructural changes were observed as a result of both drying process and in vitro gastric digestion compared to the undigested raw beetroot samples. Compared to the raw beetroots, CD beetroots exhibited the greatest changes, both before and after digestion.

\subsection{Image texture analysis}

Cell number per unit area of raw beetroot, drying beetroots (CD and FD samples) and beetroots after gastric in vitro digestion (raw180, CD180 and FD180) are presented in table 1. All beetroot drying samples present significantly higher cell number per unit of area 
$(\mathrm{p}<0.05)$ than raw beetroots. Moreover, CD samples presented significantly higher cell number $(\mathrm{p}<0.05)$ than FD samples. The highest cell number per unit of area increase was observed in CD samples ( $47 \pm 2 \%$ compared to raw samples). This result may be due to the drying causing a collapse of the cell walls thus producing a volume shrinkage that results in a greater cell number per unit ${ }^{[8,21]}$. All samples after gastric in vitro digestion present significantly lower cell number per unit $(\mathrm{p}<0.05)$ than beetroot before in vitro digestion. No significant differences ( $>0.05$ ) were observed between the cell number per unit of raw samples and all drying beetroot samples. This result may be due to the fact that in vitro digestion causes a certain disruption of the cell structure which results in a lower cell number per unit. Different values of cell number per unit compared to raw sample (34-66\% of reduction) after different treatments (inmmersion in boiling water, vacuum impregnation, freezing/thawing and compression) were also reported by Ramírez et al. ${ }^{[17]}$.

Fig 2 represents the cell area percentile profiles of raw and drying samples before (raw, CD and FD samples) and after 180 min of gastric in vitro digestion (raw180, CD180 and FD180 samples). In this figure, the percentile represents the percentage of cell whose area is equal or smaller to one value. As can be seen in fig 2, different percentile profiles were obtained for each sample.

Table 1. Cell number per unit of area of the raw and drying (CD and FD) beetroot before and after 180 min of gastric in vitro digestion. Different lowercase letter indicate significant differences $(p<0.05)$ for cell number per unit in a sample before and after in vitro digestion. Different capital letters indicate significant differences between the diferent method of processing (Tukey's test,

\begin{tabular}{cc}
\multicolumn{2}{c}{$\boldsymbol{p < 0 . 0 5 )}$} \\
\hline \hline Cell number/mm \\
\hline Raw & $289 \pm 4 \mathrm{aC}$ \\
\hline Raw 180 & $171 \pm 5 \mathrm{~b}$ \\
\hline CD & $425 \pm 1 \mathrm{aB}$ \\
\hline CD180 & $250 \pm 18 \mathrm{~b}$ \\
\hline FD & $370 \pm 40 \mathrm{aA}$ \\
\hline FD180 & $190 \pm 20 \mathrm{~b}$
\end{tabular}

The percentile profiles of raw and drying samples (CD and FD samples) were coincident until ca 25. From there onwards, two groups of samples can be observed, one consisting of raw samples, and the second, of CD and FD samples, indicating that drying processes cause similar changes in cell structure. In raw samples the percentage of larger areas was higher; for example, $80 \%$ of areas were smaller than $0.067 \mathrm{~mm}^{2}$ in raw samples and smaller than $0.016 \mathrm{~mm}^{2}$ and $0.025 \mathrm{~mm}^{2}$ in CD and FD samples, respectively. In all samples after in vitro digestion the percentage of larger areas was the lowest; for example, $80 \%$ of areas were smaller than $0.067 \mathrm{~mm}^{2}$ and $0.310 \mathrm{~mm}^{2}$ in raw samples before and after $180 \mathrm{~min}$ of gastric in 
vitro digestion, $0.016 \mathrm{~mm}^{2}$ and $0.116 \mathrm{~mm}^{2}$ in CD samples before and after 180 min of gastric in vitro digestion, $0.025 \mathrm{~mm}^{2}$ and $0.130 \mathrm{~mm}^{2}$ in raw samples before and after $180 \mathrm{~min}$ of gastric in vitro digestion. The percentile profiles of raw and raw180 samples were coincident up to ca percentile 45. However the percentile profile of drying samples (CD and FD samples with CD180 and FD180 samples) were coincident ca percentile 25 and 50, respectively.
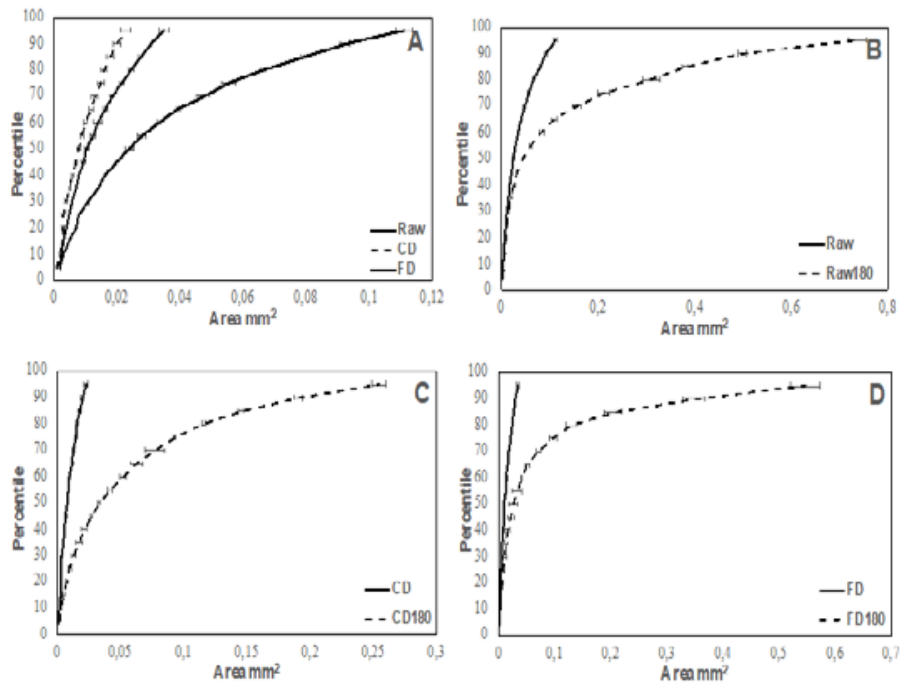

Fig. 2. Cell area percentile profiles of raw and drying samples before (A) and after (B, C and D) 180 min of gastric in vitro digestion.

\section{Conclusions}

Drying modified the microstructure of beetroots compared with that of raw beetroots. Microstructural analyses indicated significant cellular damage and changes as a result of drying and of in vitro gastric digestion. These structural modifications resulted in behavioral changes in beetroots during in vitro gastric digestion. The drying process caused cell wall collapses and gastric in vitro digestion caused a certain disruption of the cell structure Given the limited knowledge available on this subject at present, it would be interesting to investigate this area more deeply to better understand how processing and in vitro digestion can modify structural characteristics.

\section{References}

[1] Bouayed J, Hoffmann L, Bohn T. Total phenolics, flavonoids, anthocyanins and antioxidant activity following simulated gastro-intestinal digestion and dialysis of apple varieties: Bioaccessibility and potential uptake. Food Chem 2011;128(1):14-21.

[2] Saura-Calixto F. Dietary fiber as a carrier of dietary antioxidants: an essential physiological function. J Agric Food Chem 2011 59(1):43-9. 
[3] Garrett DA, Failla ML, Sarama RJ. Development of an in vitro digestion method to assess carotenoid bioavailability from meals. J Agric Food Chem 47(10):4301-9.

[4] Wootton-Beard PC, Moran A, Ryan L. Stability of the total antioxidant capacity and total polyphenol content of 23 commercially available vegetable juices before and after in vitro digestion measured by FRAP, DPPH, ABTS and Folin-Ciocalteu methods. Food Res Int 2011;44:217-24.

[5] Huang LL, Zhang M, Wang LP, Mujumdar AS, Sun DF. Influence of combination drying methods on composition, texture, aroma and microstructure of apple slices. LWT - Food Sci Technol 2012;47(1):183-8.

[6] Aguilera JM. Why food microstructure? J Food Eng. 2005;67:3-11.

[7] Nayak CA, Suguna K, Narasimhamurthy K, Rastogi NK. Effect of gamma irradiation on histological and textural properties of carrot, potato and beetroot. J Food Eng 2007;79(3):765-70.

[8] Carnachan SM, Bootten TJ, Mishra S, Monro J a., Sims IM. Effects of simulated digestion in vitro on cell wall polysaccharides from kiwifruit (Actinidia spp.). Food Chem 2012;133(1):132-9.

[9] Devaux MF, Bouchet B, Legland D, Guillon F, Lahaye M. Macro-vision and grey level granulometry for quantification of tomato pericarp structure. Postharvest Biol Technol. 2008;47(2):199-209.

[10] Brosnan, T., \& Sun, D.-W. Improving quality inspection of food products by computer vision - a review. Journal of Food Engineering, 2004; 61(1), 3-16.

[11] Rodríguez Ó, Ortuño C, Simal S, Benedito J, Femenia A, Rosselló C. Acoustically assisted supercritical CO2 extraction of cocoa butter: Effects on kinetics and quality. J Supercrit Fluids. 2014;94:30-7.

[12] Bornhorst GM, Singh RP. Kinetics of in Vitro Bread Bolus Digestion with Varying Oral and Gastric Digestion Parameters. Food Biophys. 2013;8(1):50-9.

[13] Rodríguez Ó, Santacatalina J V, Simal S, Garcia-Perez J V, Femenia A, Rosselló C. Influence of power ultrasound application on drying kinetics of apple and its antioxidant and microstructural properties. J Food Eng 2014;129:21-9.

[14] Smith BG, James BJ, Ho C a. L. Microstructural Characteristics of Dried Carrot Pieces and Real Time Observations during Their Exposure to Moisture. Int J Food Eng. 2007;3(4).

[15] Lewicki PP, Pawlak G. Effect of Drying on Microstructure of Plant Tissue. Dry Technol. 2003;21:657.

[16] Dalmau ME, Bornhorst GM, Eim V, Rosselló C, Simal S. Effects of Freezing, Freeze Drying and Convective Drying on In Vitro Gastric Digestion of Apples. Food Chem. 2017;215:7-16.

[17] Ramírez C, Troncoso E, Muñoz J, Aguilera JM. Microstructure analysis on pre-treated apple slices and its effect on water release during air drying. J Food Eng. 2011;106(3):253-61. 